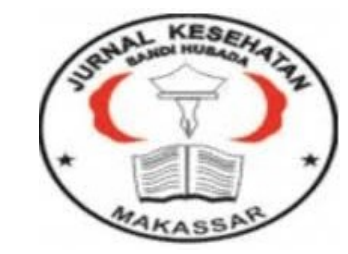

\author{
Jurnal Ilmiah Kesehatan Sandi Husada \\ hhttps://akper-sandikarsa.e-journal.id/JIKSH \\ Volume 11, Nomor 1, Juni 2020, pp;490-496 \\ p-ISSN: 2354-6093 dan e-ISSN: 2654-4563 \\ DOI: $10.35816 /$ jiskh.v10i2.335
}

\title{
Perforasi pada Penderita Apendisitis Di RSUD DR.H.Abdul Moeloek Lampung
}

Perforation in Appendicitis Patients in RSUD Dr. H. Abdul Moeloek Lampung

\begin{abstract}
Mizar Erianto ${ }^{1}$, Neno Fitriyani' ${ }^{2}$, Andi Siswandi ${ }^{3}$, Arya Putri Sukulima ${ }^{4}$
1Departemen Bedah Umum Rumah Sakit Pertamina Bintang Amin, ${ }^{2}$ Departemen Ilmu Kedokteran Komunitas, Fakultas Kedokteran Universitas Malahayati, 32Departemen Bedah Umum Rumah Sakit TNI DKT tingkat IV Bandar Lampung, ${ }^{4}$ Program studi kedokteran Fakultas Kedokteran Universitas Malahayati,
\end{abstract}

\begin{tabular}{l}
\multicolumn{1}{c}{ Artikel info } \\
\hline Artikel history: \\
Received; Mei 2020 \\
Revised: Juni 2020 \\
Accepted; Juni2020
\end{tabular}


penderita perforasi apendisitis pada penderita apendisitis akut dewasa di Rumah Sakit Umum Daerah Dr. H. Abdul Moeloek Provinsi Lampung Tahun 2017.Metode Penelitian :Jenis penelitian kuantitatif, rancangan deskriptif. Populasi seluruh pasien penderita apendisitis akut dewasa sebanyak 151 orang. Sampel sebanyak 110 orang dengan teknik random sampling. Pengambilan data menggunakan lembar Observasi data rekam medik. Teknik analisis data menggunakan uji statistik Univariat.Hasil penelitian: Distribusi frekuensi usia pasien perforasi apendisitis, sebagian besar adalah usia 20-30 tahun sebanyak 48 pasien (43,63\%). Distribusi frekuensi jenis kelamin pasien perforasi apendisitis, sebagian besar adalah laki-laki sebanyak 92 pasien (83,63\%). Distribusi frekuensi suhu tubuh pasien perforasi apendisitis, sebagian besar dengan suhu tubuh $>37,5^{\circ} \mathrm{C}$ sebanyak 103 pasien (93,63\%). Distribusi frekuensi kadar leukosit pasien perforasi apendisitis, sebagian besar dengan kadar leukosit $>18.000 / \mathrm{mm}$ sebanyak 84 pasien $(76,36 \%)$.

Keywords:

Perforasi Appendisitis;

Suhu Badan;

Leukosit;
Corsponden author:

Email: mizar.erianto@gmail.com

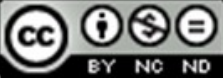

artikel dengan akses terbuka dibawah lisensi BCC BY NC ND-4.0

\section{Pendahuluan}

Apendisitis merupakan peradangan pada Apendiks yang berbahaya jika tidak ditangani dengan segera di mana terjadi infeksi berat yang bisa menyebabkan pecahnya lumen usus (Williams, 2011). Apendisitis perforasi adalah pecahnya apendiks yang sudah gangren yang menyebabkan pus masuk ke dalam rongga perut sehingga terjadi peritonitis umum. Pada dinding apendiks tampak daerah perforasi dikelilingi oleh jaringan nekrotik. Apendisitis adalah peradangan dari apendiks veriformis dan merupakan penyebab abdomen akut. Apendiks memiliki panjang sekitar $6 \mathrm{~cm}$ sampai $9 \mathrm{~cm}$ pada orang dewasa 20-30 tahun Dasar apendiks melekat pada sekum dan ujungnya memiliki beberapa posisi seperti retrosekal, pelvis, antesekal, preileal, retroileal, atau perikolik kanan.1 Prevalensi apendisitis lebih banyak di Negara maju dari pada Negara berkembang, disebabkan karena masyarakat di Negara maju kurang mengkonsumsi makanan berserat tinggi sehingga terjadi pembentukan fase fekalit lalu menjadi obstruksi lumen yang akan menyebabkan penyakit apendisitis(Tanto, etal, 2014).

Penyakit Apendisitis Menurut Kementrian Kesehtan Survey di 15 provinsi Indonesia tahun 2014 menunjukan jumlah apendisitis yang dirawat di rumah Sakit sebanyak 4.351 kasus. Jumlah ini meningkat drastis dibandingkan dengan tahun sebelumnya, yaitu sebanyak 3.236 orang. Penyakit Apendisitis Menurut Kementrian Kesehtan Survey di 15 provinsi Indonesia tahun 2014 menunjukan jumlah apendisitis yang dirawat di rumah Sakit sebanyak 4.351 kasus. Jumlah ini meningkat drastis dibandingkan dengan tahun sebelumnya, yaitu sebanyak 3.236 orang (KEMKES, 2012). (Indri, 2014) berpendapat bahwa risiko jenis kelamin pada kejadian penyakit apendisitis terbanyak berjenis kelamin laki-laki dengan presentase $72,2 \%$ sedangkan berjenis kelamin perempuan hanya $27,8 \%$. Hal ini dikarenakan laki-laki lebih banyak menghabiskan waktu diluar rumah untuk 
bekerja dan lebih cenderung mengkonsumsi makanan cepat saji, sehingga hal ini dapat menyebabkan beberapa komplikasi atau obstruksi pada usus yang bisa menimbulkan masalah pada sistem pencernaan salah satunya yaitu apendisitis.

Apendisitis merupakan masalah yang serius yang harus dicegah sedini mungkin dan salah satu cara untuk menyembuhkan apendisitis adalah dengan apendiktomi atau bedah mayor pada apendiks (Price \& Wilson, 2006). Apendisitis akut pada anamnesis dan pemeriksaan fisik merupakan dasar dalam diagnosis apendisitis dengan tingkat akurasi sebesar 7680\%. Disamping itu kemampuan dokter dalam menegakkan diagnosis apendisitis serta membedakan antara apendisitis akut dan apendisitis perforasi secara klinis sangat diperlukan, karena keduanya memiliki penanganan yang berbeda. Gejala dan tanda apendisitis yang tidak khas akan menyulitkan dokter dalam menegakkan diagnosis, sehingga dokter akan melakukan pemeriksaan penunjang untuk menegakkan diagnosis. Salah satu pemeriksaan penunjang yang dapat dilakukan adalah pemeriksaan hitung jumlah leukosit.6 8 Jumlah leukosit umumnya meningkat pada apendisitis akut yakni sekitar 10.000-18.000 sel/mm. Jumlah leukosit yang kurang dari $18.000 \mathrm{sel} / \mathrm{mm} 3$ umumnya terjadi pada apendisitis simpel dan leukosit yang lebih dari $18.000 \mathrm{sel} / \mathrm{mm}$ menunjukkan adanya perforasi(Agus, 2011).

Tujuan Penelitian ini adalah gambaran penderita apendisitis perforasi pada penderita apendisitis akut dewasa di Rumah Sakit Umum Daerah Dr. H. Abdul Moeloek Provinsi Lampung. Hasil penelitian ini dapat dijadikan sebagai informasi, sebagai masukan bagi institusi rumah sakit dalam meningkatkan pelayanan kesehatan untuk menciptakan kepuasan dan kenyamanan bagi pasien.

\section{Metode}

Jenis penelitian yang digunakan dalam penelitian ini adalah kuantitatif yaitu jenis penelitian yang mencoba mengetahui mengapa masalah kesehatan tersebut bisa terjadi kemudian melakukan analisis hubungannya. Populasi dalam penelitian ini adalah seluruh pasien penderita apendisitis akut dewasa di RSUD. dr. H. Abdul Moeloek Provinsi Lampung tahun 2017 sebanyak sebanyak 151 orang. Sampel sebanyak 110 orang. Penetapan jumlah sampel dengan menggunakan rumus slovin. Pengambilan sampel pada penelitian ini menggunakan teknik random Sampling, yaitu sampel diambil secara acak. Rancangan dalam penelitian ini adalah deskriptif yaitu suatu penelitian yang dilakukan dengan tujuan membuat gambaran atau deskriptif tentang suatu keadaan secara objektif . Pengambilan data menggunakan lembar observasi data rekam medik. Teknik analisis data menggunakan uji statistik univariat.

\section{Hasil Dan Pembahasan}

Tabel 1 Distribusi frekuensi Usia, jenis kelamin, suhu tubuh, kadar leukosit pasien perforasi apendisitis di RSUD. dr. H. Abdul Moeloek Provinsi Lampung

\begin{tabular}{lll}
\hline Usia & Frekuensi & Persentase $\%$ \\
\hline $20-30$ tahun & 48 & 43,63 \\
\hline $31-40$ tahun & 33 & 30,00 \\
\hline $41-50$ tahun & 12 & 10,91 \\
\hline$>50$ tahun & 17 & 15,45 \\
\hline Jumlah & 110 & 100,00 \\
\hline
\end{tabular}




\begin{tabular}{lcl}
\hline Jenis Kelamin & & \\
\hline Laki-laki & 92 & 83,63 \\
Perempuan & 18 & 16,37 \\
Jumlah & 110 & 100,00 \\
\hline Suhu Tubuh & \\
\hline$\leq 37,5^{\circ} \mathrm{C}$ & 7 & 6,37 \\
$>37,5^{\circ} \mathrm{C}$ & 10 & 93,63 \\
Jumlah & 110 & 100,00 \\
\hline Kadar Leukosit & & \\
\hline$<18.000 / \mathrm{mm}$ & 26 & 23,64 \\
$\geq 18.000 / \mathrm{mm}$ & 84 & 76,36 \\
Jumlah & 110 & 100,00 \\
\hline
\end{tabular}

Sumber: Data Primer 2017

\section{Pembahasan}

Berdasarkan Tabel 1 maka dapat diketahui bahwa usia pasien perforasi apendisitis di RSUD Dr. H. Abdul Moeloek Provinsi Lampung Tahun 2017, sebagian besar adalah usia 2030 tahun sebanyak 48 pasien $(43,63 \%)$, usia $31-40$ tahun 33 pasien $(30 \%)$, usia 41-50 tahun sebanyak 12 pasien $(10,91 \%)$ sedangkan usia $>50$ tahun sebanyak 17 pasien $(15,45 \%)$. Berdasarkan table 2 Diketahui bahwa jenis kelamin pasien perforasi apendisitis di RSUD. dr. H. Abdul Moeloek Provinsi Lampung Tahun 2017, sebagian besar adalah lakilaki sebanyak 92 pasien $(83,63 \%)$. Berdasarkan table 3 diketahui bahwa distribusi frekuensi suhu tubuh pasien perforasi apendisitis di RSUD. dr. H. Abdul Moeloek Provinsi Lampung Tahun 2017, sebagian besar dengan hemodinamik $>37,5^{\circ} \mathrm{C}$ sebanyak 103 pasien $(93,63 \%)$. Berdasarkan tabel 4 maka dapat diketahui bahwa kadar leukosit pasien perforasi apendisitis di RSUD. dr. H. Abdul Moeloek Provinsi Lampung Tahun 2017, sebagian besar dengan kadar leukosit $>18.000 / \mathrm{mm}$ sebanyak 84 pasien $(76,36 \%)$.

Hasil penelitian ini sesuai dengan teori yang dikemukakan (Sjamsuhidajat, 2011) yang menyatakan bahwa apendisitis dapat ditemukan pada laki-laki maupun perempuan dengan risiko menderita apendisitis selama hidupnya mencapai 7-8\%. Insiden tertinggi dilaporkan pada rentang usia 20-30 tahun. Kasus perforasi apendiks pada apendisitis akut berkisar antara $20-30 \%$ dan meningkat $32-72 \%$ pada usia lebih dari 60 tahun.

Selanjutnya Secara anatomi, orang dewasa memiliki bentuk lumen apendiks yang menyempit dibagian proksimal dan melebar pada bagian distal, sedangkan pada bayi bentuk lumen apendiks relatif lebar dibagian proksimal dan menyempit dibagian distal (Jaffe et al., 2005). Hal ini menjadi penyebab rendahnya insidensi apendisitis akut pada bayi. Risiko perforasi meningkat pada anak kurang dari 5 tahun diakibatkan proses pendindingan kurang sempurna, omentum belum berkembang, dan waktu diagnosis yang lama karena anak kurang dapat menjelaskan gejala yang dirasakan. Pada lansia lebih sering ditemukan kasus perforasi karena lumen apendiks yang sudah tertutup sepenuhnya sehingga gejala apendisitis akut yang dirasakan tidak begitu jelas dan baru dapat ditegakkan diagnosisnya saat terjadi perforasi (Shiddiq, 2013).

Berdasarkan hal tersebut bahwa pada usia dewasa lebih berisiko mengalami perforasi appendiks dikarenakan secara anatomi pada usia dewasa bentuk lumen appendiks 
menyempit pada bagian proksimal sedangkan pada usia anak melebar pada bagian distal. Pada anak-anak lemak yang membungkus appendiks (omentum) belum berkembang dan waktu diagnosis yang lama karena anak tidak dapat menjelaskan gejala yang dirasakan. Sedangkan pada usia dewasa lumen appendiks sudah tertutup sepenuhnya sehingga gejala appendisitis akut yang dirasakan tidak begitu jelas dan baru ditegakan diagnosis setelah terjadi perforasi.

Hal ini juga sesuai dengan teori (Agus, 2011) apendisitis dapat mengenai semua orang baik laki-laki maupun perempuan. Pasien apendisitis akut pada laki-laki 1,4 kali lebih banyak dari pada pasien perempuan. Angka kejadian apendektomi berdasarkan jenis kelamin didapatkan sebanyak 25\% laki-laki menjalani apendektomi dan sebanyak $12 \%$ perempuan telah menjalani apendektomi. Hal dengan penelitian yang dilakukan (Marisa,dkk, 2011) yang memperoleh hasil pada laki-laki lebih sering terjadi apendisitis perforasi sedangkan appendisitis akut lebih banyak pada perempuan. Hubungan tingginya insiden dengan jenis kelamin belum dapat diketahui penyebab yang jelas karena secara anatomi bentuk apendiks laki-laki dan perempuan sama (Notoatmodjo, 2012).

Konstipasi menyebabkan penyumbatan pada saluran appendiks. Disamping itu perlu diketahui pada perempuan sering ditemukan kasus apendisitis akut karena adanya positif palsu sebanyak 20\% terutama pada wanita usia 20-30 tahun. Positif palsu adalah keadaan pasien menunjukkan apendisitis tapi hasil pemeriksaan patologi anatomi bukan apendisitis yang disebabkan masalah ginekologis mirip apendisitis. Hal itu mungkin terjadi karena tindakan bedah harus dilakukan dengan cepat sementara penegakkan diagnosis belum dilakukan dengan baik.

Hasil penelitian ini sesuai dengan teori yang dikemukakan(Guyton, 1999) anamnesis dan pemeriksaan fisik merupakan dasar dalam diagnosis apendisitis dengan tingkat akurasi sebesar 76-80\%. Jumlah leukosit umumnya meningkat pada apendisitis akut yakni sekitar 10.000-18.000 sel/mm3. Jumlah leukosit yang kurang dari $18.000 \mathrm{sel} / \mathrm{mm} 3$ umumnya terjadi pada apendisitis simpel dan leukosit yang lebih dari $18.000 \mathrm{sel} / \mathrm{mm} 3$ menunjukkan adanya perforasi Calista (Berger,etal, 2010).Pasien dengan apendisitis pada umumnya mengalami leukositosis, yaitu peningkatan jumlah leukosit diatas $10.000 \mathrm{sel} / \mathrm{mm} 3$.

Berdasarkan penelitian yang dilakukan Andi baso (2015). dengan menganalisis leukosit pada apendisitis akut dan perforasi, memperoleh hasil jumlah leukosit 10.000-18.000 sel/mm3 banyak ditemukan pada pasien apendisitis akut yaitu sebesar 75,7\% dan jumlah leukosit $>18.000 \mathrm{sel} / \mathrm{mm} 3$ banyak ditemukan pada pasien apendisitis perforasi sebesar 90,7\%(Calista, 2015). Hal ini sejalan dengan penelitian yang dilakukan (Yulianto, etal, 2016) tentang Faktor Prediksi Perforasi Apendiks pada Penderita Apendisitis Akut Dewasa di RS Al-Ihsan Kabupaten Bandung. Diketahui proporsi faktor prediksi perforasi apendiks yang lebih banyak terdapat dalam grup kasus adalah usia kurang dari 55 tahun (97\%), tidak demam (56\%), jumlah leukosit di atas 11.500/mm3 (86\%).

Berdasarkan hal tersebut peneliti berpendapat bahwa perforasi apendik dapat ditemukan pada laki-laki maupun perempuan dengan risiko menderita apendisitis selama hidupnya mencapai 78\%. Insiden tertinggi dilaporkan pada rentang usia 20-30 tahun. Diagnosis apendisitis ditegakkan dengan riwayat penyakit, pemeriksaan fisik, pemeriksaan laboratorium, dan ultrasonography (USG).

Pemeriksaan suhu tubuh termasuk dalam salah satu kriteria pada skor alvarado untuk penegakkan diagnosis apendisitis. Suhu tubuh $<37^{\circ} \mathrm{C}$ didapatkan pada pasien apendisitis tanpa komplikasi dan pada kasus perforasi terdapat demam tinggi dengan rata-rata 
$38,3^{\circ} \mathrm{C}$. Kadar leukosit secara signifikan lebih tinggi pada kasus perforasi dibandingkan dengan tanpa perforasi. Pada kasus perforasi, apendiks mengalami ruptur, pecah atau berlubang dan kemudian pus yang terdapat didalam lumen appendiks akan keluar, menyebar ke organ-organ lain maupun didalam fossa apendiks vermiformis sehingga dapat mengakibatkan peritonitis, serta memungkinkan bakteri akan berkembang dan menimbulkan infeksi yang lebih banyak. Keadaan tersebut akan merangsang respon imun tubuh dengan lebih banyak menghasilkan leukosit yang berfungsi sebagai pertahanan terhadap agen-agen infeksius. Jumlah leukosit dalam batas normal yang banyak ditemukan pada apendisitis akut dapat dipengaruhi pemakaian antibiotik secara bebas oleh pasien sebelum masuk rumah sakit

\section{Simpulan Dan Saran}

Hasil penelitian menunjukkan bahwa usia pasien perforasi apendisitis sebagian besar adalah usia 20-30 tahun sebanyak 48 pasien, jenis kelamin laki-laki sebanyak 92 pasien, suhu tubuh $>37,5^{\circ} \mathrm{C}$ sebanyak 103 pasien dan kadar leukosit $>18.000 / \mathrm{mm}$ sebanyak 84 pasien. Diharapkan meningkatkan perkembangan ilmu pengetahuan dalam pengobatan pasien perforasi apendik, serta bagi petugas kesehatan agar dapat memberikan informasi yang akurat mengenai perforasi apendik melalui upaya preventif dan promotif seperti penyuluhan kesehatan terkait tentang bahaya perforasi apendik.

\section{Daftar Rujukan}

Agus, R. (2011). Aplikasi Metodologi penelitian kesehatan. Yogyakarta: Nuha Medika, 102. Berger, D. H., \& Jaffe, B. M. (2010). The Appendix. Dalam: Brunicardi FC, Andersen DK. Billiar TR, Dunn DL, Hunter JG, Matthews JB, Pallock RE, editor. Schwartz's ....

Calista, P. (2015). Karakteristik Penderita Apendisitis Akut di Rumah Sakit Immanuel Bandung Periode 1 Januari 2013-30 Juni 2013. Universitas Kristen Maranatha.

Guyton, A. C. (1999). Fisiologi manusia dan mekanisme penyakit. EGC.

Indri, U. V. (2014). Hubungan antara nyeri, kecemasan dan lingkungan dengan kualitas tidur pada pasien post operasi apendisitis. Riau University.

Jaffe, B. M., Berger, D. H., Brunicardi, F. C., Andersen, D. K., Billiar, T. R., Dunn, D. L., ... Pollock, R. E. (2005). Schwartz's principles of surgery.

KEMKES, R. I. (2012). Buletin Jendela Data dan Informasi Kesehatan: Penyakit tidak Menular. Jakarta: Arsip KEMKES RI. Diperoleh Dari: Http://Www. Depkes. Go. Id/Download. Php.

Marisa, H. I. J., \& RS, M. (2011). Batas angka leukosit antara appendisitis akut dan appendisitis perforasi di rumah sakit umum daerah tugurejo semarang selama Januari 2009-Juli 2011. Jurnal Kedokteran Muhammadiyah, 1.

Notoatmodjo, S. (2012). Promosi kesehatan dan perilaku kesehatan, Jakarta: Rineka Cipta. Prince, SA (2005). Patofisiologi: Konsep Klinis Proses-Proses Penyakit.

Price \& Wilson. (2006). Patofisiologi konsep klinis proses-proses penyakit. Jakarta: EGC.

Shiddiq, M. (2013). Suhu Tubuh Dan Nilai Granulosit Praoperasi Pasien Apendisitis Akut Berkomplikasi Di Rsud Dokter Soedarso Pontianak Tahun 2012. Jurnal Mahasiswa PSPD FK Universitas Tanjungpura, 2(1).

Sjamsuhidajat, R. (2011). Buku ajar ilmu bedah Sjamsuhidajat-de Jong. Edisi Ke-3. Jakarta: EGC, 706-722.

Tanto, C., Liwang, F., Hanifati, S., \& Pradipta, E. A. (2014). Kapita selekta kedokteran. 
Jakarta: Media Aesculapius, 329-330.

Williams, L. \& W. (2011). Memahami berbagai macam penyakit. Jakarta Barat: PT Indeks.

Yulianto, F. A., Sakinah, R. K., Kamil, M. I., \& Wahono, T. Y. M. (2016). Faktor Prediksi Perforasi Apendiks pada Penderita Apendisitis Akut Dewasa di RS Al-Ihsan Kabupaten Bandung Periode 2013-2014. Global Medical \& Health Communication, 4(2), 114-120. 